\title{
Conductivity Characteristics and Vis-NIR Absorption Spectra of Polypyrrole Films at Higher Temperatures
}

\author{
Yongfang LI, Kenichi Imaeda, * and Hiroo INOKUCHI* \\ Institute of Chemistry, Academia Sinica, Beijing 100080, China \\ * Institute for Molecular Science, Myodaiji, Okazaki 444, Japan
}

(Received July 10, 1995)

\begin{abstract}
Conductivity and Vis-NIR absorption spectra of polypyrrole films, doped with $\mathrm{TsO}^{-}, \mathrm{ClO}_{4}{ }^{-}, \mathrm{Cl}^{-}, \mathrm{NO}_{3}{ }^{-}$, were measured from room temperature to over $200^{\circ} \mathrm{C}$. The conductivity behavior of the PPy films with the increase of temperature much depends on the nature of the counter-anions. For $\left.\mathrm{PPy}_{(\mathrm{TsO}}^{-}\right)$film, there seems a phase transition at $c a$. $363 \mathrm{~K}$, over which the conductivity increases with temperature more quickly and a red shift of its absorption peak in the NIR region occurs.

KEY WORDS Polypyrrole / Conductivity / Higher Temperature / Vis-NIR Absorption Spectra / Temperature Dependence /
\end{abstract}

Conducting polypyrrole (PPy) has drawn much attention in the past fifteen years because of its easy preparation by electrochemical methods, ${ }^{1,2}$ good stability in its oxidized state $^{3}$ and its interesting structure, ${ }^{4-7}$ electronic $^{8,9}$ and electrochemical properties. ${ }^{10,11} \mathrm{~A}$ great deal of effort has been devoted to the structural analysis of PPy. Mitchell et al. found that PPy possesses anisotropic structure based on the results of X-ray diffraction. ${ }^{4} \mathrm{Li}$ et al. confirmed the anisotropic structure with the conductivity measurement ${ }^{9}$ and with the observation of shrinkage of the $\mathrm{PPy}\left(\mathrm{NO}_{3}{ }^{-}\right.$) (polypyrrole doped with $\mathrm{NO}_{3}{ }^{-}$) film after alkali treatment. ${ }^{7}$ Moreover, it was found that the behavior of the anisotropy of PPy depended on the nature of the counter-anions doped during polymerization. ${ }^{7}$ In recent years, two doping structures of $\mathrm{PPy}\left(\mathrm{NO}_{3}{ }^{-}\right)$were suggested based on its two electrochemical reduction processes in a neutral aqueous solution. ${ }^{10}$ The two doping structures are the oxidized conjugated chain doped with counter-anions (Structure I) and the protonated PPy chain doped with counteranions (Structure II):

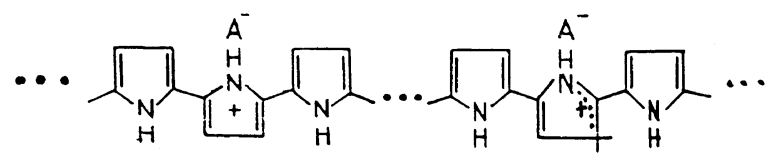

Structure I Structure II

The ratio of the doping degree of the two doping structures in PPy depends on the polymerization conditions. ${ }^{7}$ Moreover, the quantity of the PPy films is tightly related to the doping degrees of Structure I and Structure II. For the $\mathrm{PPy}\left(\mathrm{TsO}^{-}\right)$film prepared from $\mathrm{TsONa}$ aqueous solution, which is flexible and highly conductive, the doping degree of Structure I is over 0.30 and that of Structure II is less than 0.02. While for the $\mathrm{PPy}\left(\mathrm{NO}_{3}{ }^{-}\right)$ film prepared from $\mathrm{NaNO}_{3}$ aqueous solution, which is brittle and less conductive, the doping degree of Structure I is less than 0.15 and that of Structure II is $c a$. $0.08-0.10 .{ }^{7}$ So the higher the doping degree of Structure I in the PPy film, the better the quantity of the film.

In addition, it is well known that the morphology, conductivity and density of PPy films are dependent on its electropolymerization conditions, such as electrolyte anions, ${ }^{2,12}$ solvents, ${ }^{13}$ and temperature etc. ${ }^{14}$ But more work is needed to clarify their structural differences.

The conductivity behavior of $\mathrm{PPy}\left(\mathrm{NO}_{3}{ }^{-}\right)$at higher temperature has been studied recently. A characteristic conductivity drop at $c a .110^{\circ} \mathrm{C}$ and a mass loss of TGA at that temperature supported the view point of two doping structures. ${ }^{6}$ This indicates that the conductivity measurement at higher temperature may be a valuable way to investigate the structural characteristics of PPy. Moreover, Vis-NIR absorption spectroscopy has been widely used to study the structure. So, the temperature dependence of the conductivity and the absorption spectra were studied at higher temperatures for the polypyrrole films doped with $\mathrm{TsO}^{-}, \mathrm{ClO}_{4}{ }^{-}, \mathrm{Cl}^{-}$, or $\mathrm{NO}_{3}{ }^{-}$counter-anions.

\section{EXPERIMENTAL}

Polypyrrole films were electropolymerized at a constant current of $2 \mathrm{~mA} \mathrm{~cm} \mathrm{~cm}^{-2}$ in the aqueous solution of $0.1 \mathrm{M}$ pyrrole, $0.2 \mathrm{M}$ supporting electrolyte at $\mathrm{pH} 3$. The films for conductivity measurement were prepared on stainless steel electrode. The charge consumed during polymerization was $c a .8 \mathrm{C} \mathrm{cm}^{-2}$ (film thickness is ca. $30 \mu \mathrm{m}$ ). While the films for the spectroscopy were deposited on ITO electrode with a thickness of $c a .0 .4 \mu \mathrm{m}$. The conductivity was measured with four-probe method under vacuum of $10^{-3}$ Torr in the temperature range from room remperature to $c a .250^{\circ} \mathrm{C}$. The Vis-NIR absorption spectra were taken by Shimadzu UV-3101 PC UV-Vis-NIR Scanning Spectrophotometer. Differential scanning calorimetry (DSC) and thermogravimetry analysis (TGA) were carried out with a DuPont 9900 Thermal Analyser.

\section{RESULTS AND DISCUSSION}

\section{$P P y\left(T s O^{-}\right)$}

The polypyrrole film doped with tosylate anions, PPy $\left(\mathrm{TsO}^{-}\right)$, is a representative PPy film possessing good conductivity and stability. So the study on its structure has drawn much attention. Here the temperature dependence of its conductivity under vacuum at higher 


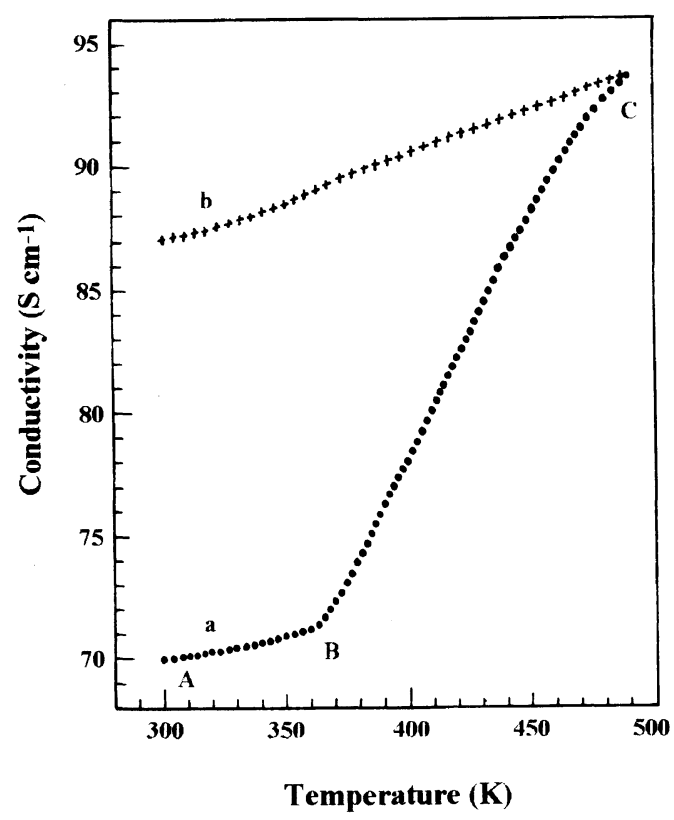

Figure 1. Temperature dependence of the conductivity of $\mathrm{PPy}\left(\mathrm{TsO}^{-}\right)$ film: (a) with increasing temperature; (b) with decreasing temperature.

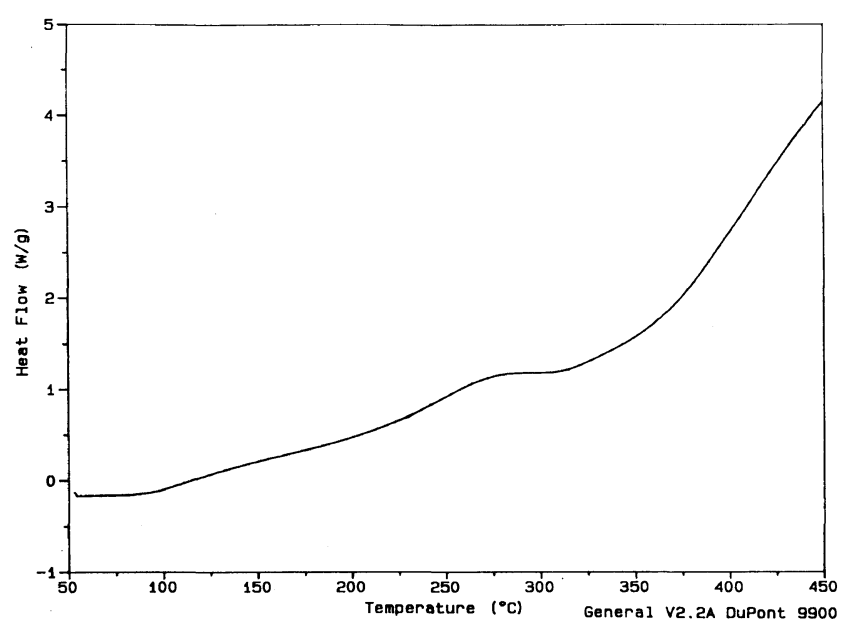

Figure 2. DSC curve of $\mathrm{PPy}\left(\mathrm{TsO}^{-}\right)$film.

temperatures was measured, as shown in Figure 1. The behavior of Curve (a) in Figure 1, which is taken as increasing temperature, is quite different from that of PPy $\left(\mathrm{NO}_{3}{ }^{-}\right){ }^{6}$ The conductivity keeps increasing till $490 \mathrm{~K}$, indicating that $\mathrm{PPy}\left(\mathrm{TsO}^{-}\right)$is stable at the higher temperature range. More interesting is the phase-transition-like phenomenon at $c a .363 \mathrm{~K}$. In section AB (below $363 \mathrm{~K}$ ), the conductivity slowly increases with temperature. When the temperature rises further beyond $363 \mathrm{~K}$, the conductivity behavior seems going into a new phase and it increases more quickly. The DSC curve of the $\mathrm{PPy}\left(\mathrm{TsO}^{-}\right)$film also shows a baseline change, which implies a change of heat capacity, at $363 \mathrm{~K}$ as increasing temperature (see Figure 2). The DSC and TGA (see Figure 3(a)) results also show the stability of $\mathrm{PPy}\left(\mathrm{TsO}^{-}\right)$below $230^{\circ} \mathrm{C}(503 \mathrm{~K})$. The $\mathrm{DSC}$ peak at around $272^{\circ} \mathrm{C}(545 \mathrm{~K})$ is corresponding to some weight loss in TGA curve.

To elucidate the structural change of $\mathrm{PPy}\left(\mathrm{TsO}^{-}\right)$in the temperature range concerned above, the Vis-NIR absorption spectra were recorded at various temperatures with increasing temperature (see Figure 4). The

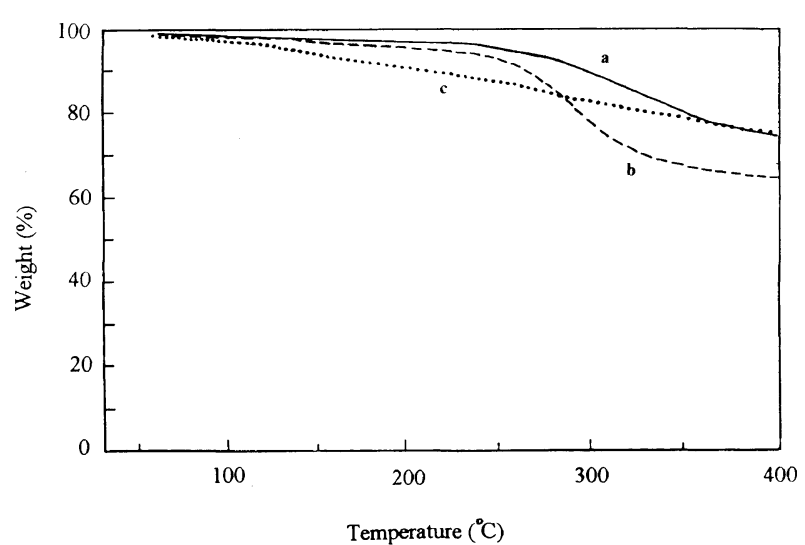

Figure 3. TGA curves of (a) $\mathrm{PPy}\left(\mathrm{TsO}^{-}\right)$, (b) $\mathrm{PPy}\left(\mathrm{ClO}_{4}^{-}\right)$, and (c) $\operatorname{PPy}\left(\mathrm{Cl}^{-}\right)$.

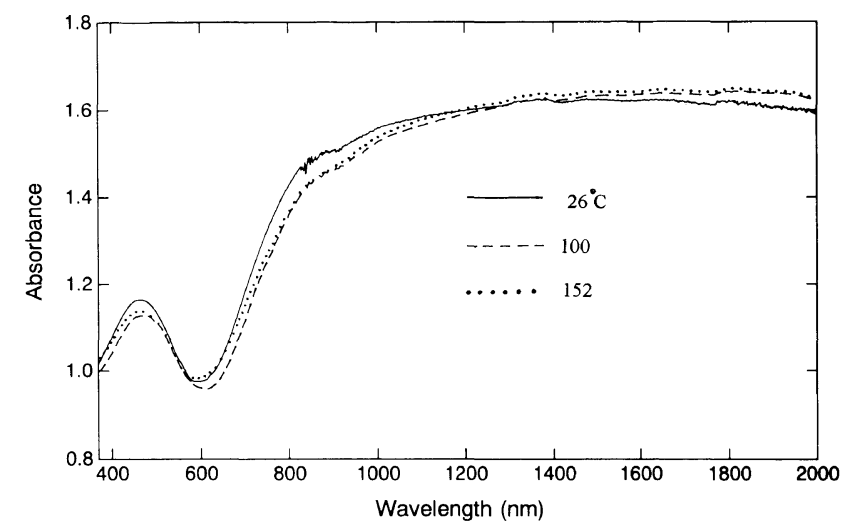

Figure 4. Vis-NIR absorption spectra of $\mathrm{PPy}\left(\mathrm{TsO}^{-}\right)$film at higher temperatures.

spectra remain unchanged below $363 \mathrm{~K}$. When the temperature rises over $370 \mathrm{~K}$, the absorption peaks in the near-infrared ragion shift to longer wavelength (shifted from $c a .1400 \mathrm{~nm}$ to $c a .1800 \mathrm{~nm}$ ). The red shift of the NIR absorption indicates that some structural change occurred at the higher temperature.

The temperature dependence of conductivity with decreasing temperature from $490 \mathrm{~K}$ to $300 \mathrm{~K}$ was also studied, as shown in Curve (b) of Figure 1. The conductivity decreases quite slowly compared with the quick increase as increasing temperature. When the temperature returns to room temperature, the conductivity is still at a higher value. However, the value decreases slowly with time and it returns to its original value after $20 \mathrm{~h}$. The hysteresis phenomenon indicates that the high temperature phase of $\mathrm{PPy}\left(\mathrm{TsO}^{-}\right)$is quasi-stable. Some energy barrier may exist when change-back from the chain structure at high temperature to that at room temperature.

\section{$\operatorname{PPy}\left(\mathrm{NO}_{3}{ }^{-}\right)$}

The conductivity behavior of $\operatorname{PPy}\left(\mathrm{NO}_{3}{ }^{-}\right)$at higher temperatures has been studied previously. ${ }^{6} \mathrm{~A}$ drop of conductivity by $3-4$ times at $c a .110^{\circ} \mathrm{C}$ was observed. The deprotonation of Structure II was confirmed with TGA analysis. ${ }^{6}$ The chemical change at over $110^{\circ} \mathrm{C}$ can be expressed as:

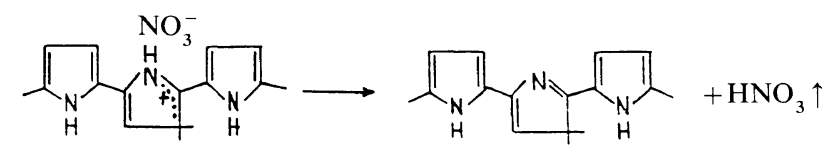

Polym. J., Vol. 28, No. 7, 1996 


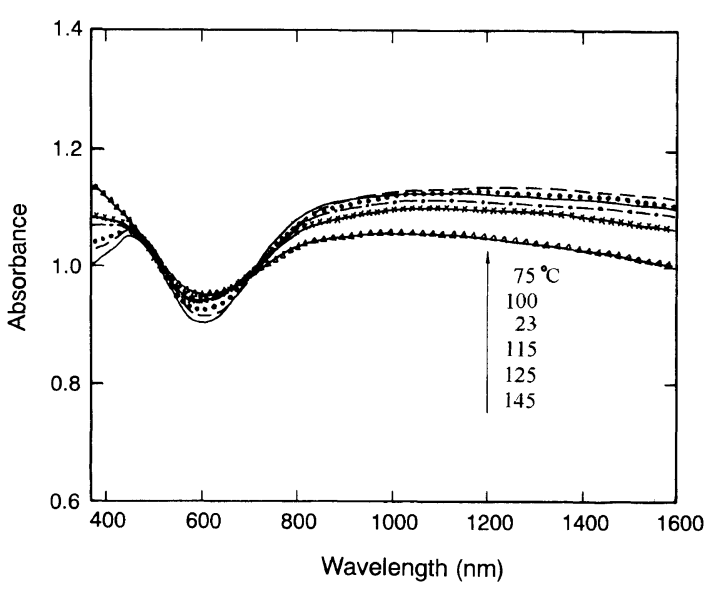

Figure 5. Vis-NIR absorption spectra of $\mathrm{PPy}\left(\mathrm{NO}_{3}{ }^{-}\right)$film at higher temperatures.

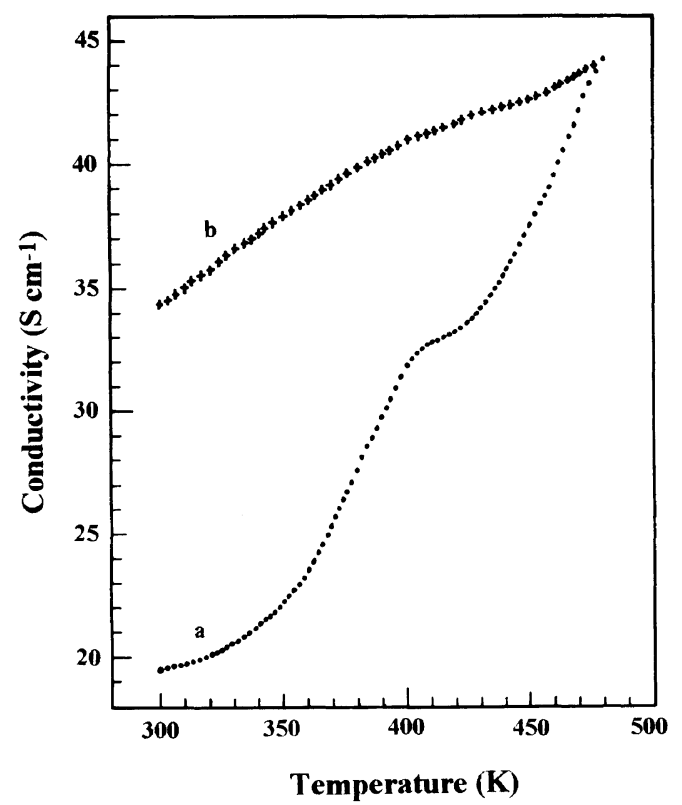

Figure 6. Temperature dependence of the conductivity of $\mathrm{PPy}\left(\mathrm{ClO}_{4}{ }^{-}\right)$ film: (a) with increasing temperature; (b) with decreasing temperature.

In order to see the spectral change with the deprotonation of Structure II, the absorption spectra were measured. The results are shown in Figure 5. The absorbance in the NIR region changes very little as the temperature rises from $23^{\circ} \mathrm{C}$ to $75^{\circ} \mathrm{C}$, although it increases a little bit. But it turns decreasing after the temperature rises over $100^{\circ} \mathrm{C}$ where the deprotonation of Structure II occurs. ${ }^{6}$ The absorbance drops further with the increase of temperature after the deprotonation. So the deprotonated structure of $\mathrm{PPy}\left(\mathrm{NO}_{3}{ }^{-}\right)$is unstable at higher temperatures from the view point of the absorption spectra.

\section{$\mathrm{PPy}\left(\mathrm{ClO}_{4}^{-}\right)$}

Figure 6 shows the temperature dependence of the conductivity of $\mathrm{PPy}\left(\mathrm{ClO}_{4}{ }^{-}\right)$at higher temperatures. The conductivity behavior as increasing temperature (Curve a) is a little similar to that of $\mathrm{PPy}\left(\mathrm{TsO}^{-}\right)$, except for the "S" curve at around $406 \mathrm{~K}$. So, some change of the chain structure of $\mathrm{PPy}\left(\mathrm{ClO}_{4}{ }^{-}\right)$may take place at higher temperatures. Curve (b) shows the hysteresis as decreasing temperature. The "S" part in Curve (a) may be resulted from some deprotonation of Structure II in $\mathrm{PPy}\left(\mathrm{ClO}_{4}{ }^{-}\right)$,



Figure 7. Vis-NIR absorption spectra of $\mathrm{PPy}\left(\mathrm{ClO}_{4}{ }^{-}\right)$film at higher temperatures.

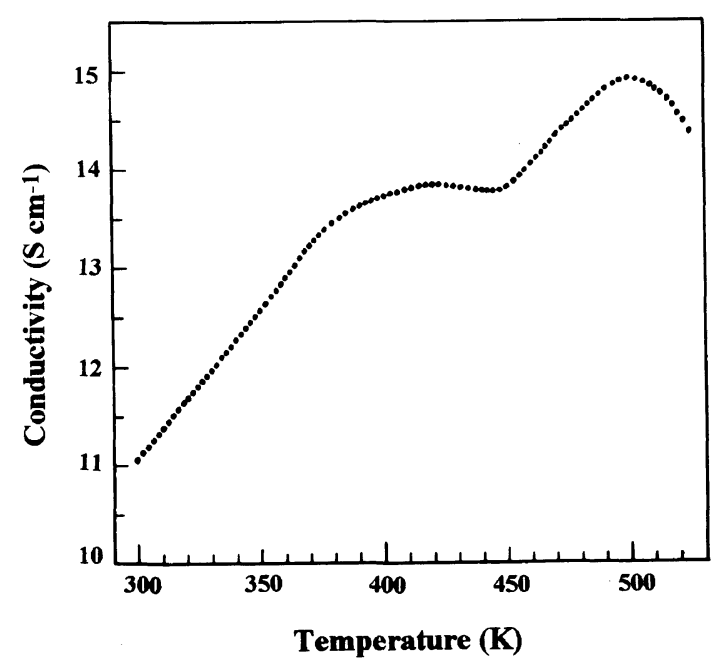

Figure 8. Temperature dependence of the conductivity of $\operatorname{PPy}\left(\mathrm{Cl}^{-}\right)$ film with increasing temperature.

similar to that of $\operatorname{PPy}\left(\mathrm{NO}_{3}{ }^{-}\right){ }^{6}$ The deprotonation is supported by the weight loss at $406 \mathrm{~K}\left(133^{\circ} \mathrm{C}\right)$ in the TGA curve of $\mathrm{PPy}\left(\mathrm{ClO}_{4}{ }^{-}\right)$in Figure 3(b). The spectral change of $\mathrm{PPy}\left(\mathrm{ClO}_{4}{ }^{-}\right)$is shown in Figure 7. The red shift and the increasement of the NIR absorbance at $100^{\circ} \mathrm{C}(373 \mathrm{~K})$ are similar to those of $\mathrm{PPy}\left(\mathrm{TsO}^{-}\right)$. But when the temperature reaches the " $\mathrm{S}$ " region $\left(140^{\circ} \mathrm{C}\right.$ here), the NIR absorbance turns to decrease. It drops further when the temperature rises to $180^{\circ} \mathrm{C}$. The spectral change at higher than $140^{\circ} \mathrm{C}$ agrees with the assumption that deprotonation occurs in the "S" region, when compared with the spectral change of $\mathrm{PPy}\left(\mathrm{NO}_{3}{ }^{-}\right)$at over $110^{\circ} \mathrm{C}^{6}$

\section{$\mathrm{PPy}\left(\mathrm{Cl}^{-}\right)$}

Figure 8 shows the temperature dependence of the conductivity of $\mathrm{PPy}\left(\mathrm{Cl}^{-}\right)$with increasing temperature. The behavior of the conductivity is a little similar to that of $\mathrm{PPy}\left(\mathrm{NO}_{3}{ }^{-}\right),{ }^{6}$ except for the less amount of decrease at $110-180^{\circ} \mathrm{C}$. The tendency of the absorbance change in the NIR region (see Figure 9) is also similar to that of $\mathrm{PPy}\left(\mathrm{NO}_{3}{ }^{-}\right)$. TGA result of $\mathrm{PPy}\left(\mathrm{Cl}^{-}\right)$in Figure 3(c) shows some weight loss in the temperature range. So the deprotonation of $\mathrm{PPy}\left(\mathrm{Cl}^{-}\right)$is proposed at the temperatures from $110-180^{\circ} \mathrm{C}$. The conductivity decreased monotonously when decreasing temperature from $250^{\circ} \mathrm{C}$ to room temperature. Obviously, irreversible structural change occurred at higher temperature for $\mathrm{PPy}\left(\mathrm{Cl}^{-}\right)$ film. 


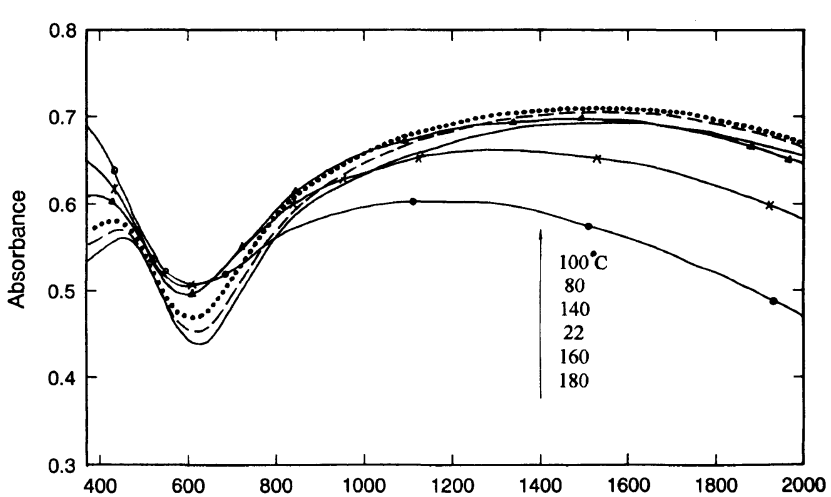

Figure 9. Vis-NIR absorption spectra of $\mathrm{PPy}\left(\mathrm{Cl}^{-}\right)$film at higher temperatures.

\section{SUMMARY}

The temperature dependence of conductivity and VisNIR absorption spectra of polypyrrole films were measured from room temperature to over $200^{\circ} \mathrm{C}$. The results show that the properties are related to the nature of its counter-anions. A phase-transition-like phenomenon was observed for PPy(TsO $\left.{ }^{-}\right)$film at $c a .363 \mathrm{~K}$ and for PPy $\left(\mathrm{ClO}_{4}{ }^{-}\right)$at $c a .406 \mathrm{~K}$. A red shift of NIR absorption occurs at higher temperature after the phase transition. The deprotonation takes place for $\mathrm{PPy}\left(\mathrm{NO}_{3}{ }^{-}\right)$at $c a$. $380 \mathrm{~K}$, for $\mathrm{PPy}\left(\mathrm{ClO}_{4}{ }^{-}\right)$at ca. $406 \mathrm{~K}$ and for $\mathrm{PPy}\left(\mathrm{Cl}^{-}\right)$ at around $400 \mathrm{~K}$. The NIR absorption decreases after the deprotonation.

Acknowledgement. This work was partly supported by the National Natural Science Foundation of China.

\section{REFERENCES}

1. A. F. Diaz, K. K. Kanazawa, and G. P. Gardini, J. Chem. Soc., Chem. Commun., 625 (1979).

2. R. Qian and J. Qiu, Polym. J., 19, 157 (1987).

3. K. K. Kanazawa, A. F. Diaz, R. H. Geiss, W. D. Gill, J. F. Kwak, J. A. Logan, J. F. Rabolt, and G. B. Street, J. Chem. Soc., Chem. Commun., 854 (1979).

4. G. R. Mitchell and A. Geri, J. Phys. D: Appl. Phys., 20, 1346 (1987).

5. R. Yang, K. M. Dalsin, D. F. Evans, L. Christensen, and W. A. Hendrickson, J. Phys. Chem., 93, 511 (1989).

6. Y. Li, R. Qian, K. Imaeda, and H. Inokuchi, Polym. J., 26, 535 (1994).

7. Y. Li, J. Ouyang, and J. Yang, Synth. Met., 74, 49 (1995).

8. P. Batz, D. Schmeisser, and W. Gopel, Phys. Rev. B, 43, 9178 (1991).

9. Y. Li and R. Qian, Synth. Met., 55-57, 3637 (1993).

10. Y. Li and R. Qian, J. Electroanal. Chem., 362, 267 (1993).

11. Y. Li and R. Qian, Synth. Met., 28, C 127 (1989).

12. A. F. Diaz and K. K. Kanazawa, Extended Linear Chain Compounds, 3, 417 (1987).

13. D. J. Walton, D. M. Hadingham, C. E. Hall, I. V. F. Viney, and A. Chyla, Synth. Met., 41-43, 295 (1991).

14. D. S. Maddison and J. Unsworth, Synth. Met., 30, 47 (1989). 